\title{
Comparison of Antibacterial Activity of Fungal Chitosan and Some Preservatives Against Some Foodborne Pathogenic Bacteria
}

\author{
R.A. ${ }^{1}$, Zaghloul, H.E., Abou-Aly, T.M., El-Housseiny, G.A. ${ }^{2}$ \\ Ghonaimy* and Ashry, Noha, M. \\ Fac. Agric., Moshtohor, Benha University and *Food Techn. \\ Res. Inst. (FTRI), Agric.Res. Center (ARC), Cairo, Egypt.
}

\begin{abstract}
A NTIBACTERIAL activity of chitosan, sodium nitrite and A sodium benzoate were studied by disc diffusion assay. Inhibition percentage, minimal inhibitory concentration and effect of MIC of chitosan on the survival of pathogenic bacterial strains were compared. Results showed that chitosan, sodium benzoate and sodium nitrite exhibited antibacterial activity against all the tested pathogens, namely E. coli, S. typhimurium, B. cereus and Staph. aureus. Inhibition of all strains increased with increasing concentrations of fungal chitosan and preservative.
\end{abstract}

Keywords: Chitosan, Antibacterial activity, Preservatives, Minimal inhibitory concentration, E. coli, S. typhimurium, B. cereus and Staph. aureus.

Chitosan is a copolymer of D-glucoseamine and N-acetyl-D-glucoseamine units, drived from the deacetylation of chitin in the presence of hot alkali. Chitosan and its derivatives can be variously used as a permeability control agent, an adhesive, a paper sizing agent, a fining agent, flocculating and chelating agents, an antimicrobial compound and a chromatographic support (Shahidi et al, 1999). Chitosan has antifungal activity against many plant pathogens (El-Mougy et al., 2002). Chitosan is a non-toxic compound which was reported to induce resistance against soil born fungi (Benhamou \& Theriault, 1992 and Abd-Elkareem, 2002). The aim of this work was to study the effect of fungal chitosan on some Gram-positive and Gram-negative food-borne pathogenic bacteria compared to selected chemical preservatives.

\section{Materials and Methods}

\section{Preparation of chitosan solution}

Chitosan was obtained from sphinx for international Trade Company, Cairo, Egypt. Stock chitosan suspension 2\% (w/v) was prepared in 1\% (v/v) acetic acid. The applied concentrations of chitosan were 750, 1000, 1500, $2000 \mathrm{ppm}$. The chitosan suspension was stirred overnight at room temperature, and filtered to remove potential impurities according to $\mathrm{Wu}$ et al. (2005). 
Preparation of preservatives

Sodium benzoate and sodium nitrite were prepared by dissolving in liquid medium. The final concentrations of sodium benzoate were 5000, 7500, 10000 and $12500 \mathrm{ppm}$ while, sodium nitrite concentrations were 500, 1000, 1500 and 2000 ppm according to the method described by Stanojevic et al. (2010). Preservative solutions were heat-treated at $80^{\circ} \mathrm{C}$ for $15 \mathrm{~min}$ before testing.

Determination of antibacterial activity of fungal chitosan and some preservatives by disc diffusion method

Two concentrations of chitosan $(750 \& 1000 \mathrm{ppm})$, sodium benzoate $(5000 \&$ $10000 \mathrm{ppm})$ and sodium nitrate (1000 \& $2000 \mathrm{ppm})$ were applied for disc diffusion. Petri dishes containing trypton soy agar medium were individually inoculated with the pathogenic bacteria (E. coli, Salmonella typhimurium, B. cereus and Staph. aureus then the impregnated discs were added and the plates were incubated at $37{ }^{\circ} \mathrm{C}$ for $24 \mathrm{~h}$ according to Logesh et al. (2012). The zone of inhibition was measured and the results were recorded.

Determination of antibacterial activity of the produced chitosan as compared with some preservatives by optical density

The minimal inhibitory concentration was defined as the lowest concentration of an antimicrobial agent at which there was no visible growth of the microbe.

Chitosan was added to tryptic soy broth (TSB) to give a final chitosan concentration of $2000 \mathrm{ppm}(0.2 \% \mathrm{w} / \mathrm{v})$. The $\mathrm{pH}$ of the broth was adjusted to 4.5 with $1 \mathrm{NHCl}$ before autoclaving at $121{ }^{\circ} \mathrm{C}$ for 15 min according to Balicka et al. (2005) and dispensed at $10 \mathrm{ml}$ per test tube. Different quantities of preservatives were added to test tubes to reach the final concentration. One tenth $\mathrm{ml}$ of the pathogenic bacterial culture approximately $\left(10^{9} \mathrm{CFU} / \mathrm{mL}\right)$ was added to $10 \mathrm{~mL}$ broth medium supplemented with preservatives and incubated at $37{ }^{\circ} \mathrm{C}$ for $48 \mathrm{~h}$. MIC was calculated as the concentration, which inhibits $95 \%$ of bacterial growth (Barakat, 2010). At the end of the incubation period, turbidity was determined by measuring the absorbance at $600 \mathrm{~nm}$ using a spectrophotometer according to the method described by Theis et al. (2003). The inhibition percentage was calculated using the following equation.

$$
\text { Inhibition percentage }=\frac{\mathrm{OD}^{*} \text { control positive }- \text { OD test }}{\text { OD control positive }} \quad \mathrm{X} 100
$$

*OD: Optical density

Inhibitory effect of chitosan and some preservatives on survival of pathogenic bacteria

The antimicrobial activity of chitosan solution against some pathogenic bacteria was determined by plate counts. Ten $\mathrm{ml}$ of tryptic soy broth supplemented with MIC of chitosan, sodium nitrate or sodium benzoate were 
individually inoculated with $0.1 \mathrm{ml}$ of the each of the pathogenic bacterial cultures. Non- supplemented medium was used as control. The inoculated tubes were incubated at $37^{\circ} \mathrm{C}$ for $48 \mathrm{~h}$ with cell counts taken after, zero, 6, 12, 18, 24, 30, 36, 42 and $48 \mathrm{hr}$.The inhibition ratios were calculated with the following formula according to the method described by Khalaf (2004):

$$
\text { Inhibition percentage }=\frac{\text { Control count }- \text { treatment count }}{\text { Control count }} \quad \text { X100 }
$$

\section{Results and Discussion}

\section{Antibacterial activity of chitosan and some preservatives}

Data in Fig. 1a\&b show that increasing the concentrations of chitosan and preservatives increased the antibacterial activity for E. coli, S. typhimurium, B. cereus and Staph. aureus. This result is in harmony with Guirguis et al. (2013) who found that increasing the concentration of chitosan led to increasing in the antimicrobial activity for $S$. aureus and B. subtilis.

Concentration of 1000 and 2000 ppm for sodium benzoate and sodium nitrite, respectively, gave higher inhibition zones for all tested bacteria compared to fungal chitosan at $1000 \mathrm{ppm}$. In general, sodium benzoate at 10,000 ppm gave the highest inhibition zone against E. coli, S. typhimurium, B. cereus and Staph. aureus being 19,16, 15 and $13 \mathrm{~mm}$, respectively, while, the fungal chitosan at 1000 ppm gave antibacterial activity being 8, 6, 13 and $11 \mathrm{~mm}$, respectively.

This result is in agreement with Islam et al. (2011) who studied different concentrations of chitosan namely, 400, 600, 800 and $1000 \mathrm{ppm}$. They found that zone of inhibition (mm) was 10, 12, 13 and 13, respectively for Staph. aureus while the zone of inhibition ( $\mathrm{mm}$ ) was $8,8,10,10$, respectively for E. coli. Data recorded that fungal chitosan at concentration $1000 \mathrm{ppm}$ exhibited antibacterial activity against Gram + pathogens (B. cereus and Staph. aureus) greater than Gram - pathogens (E. coli and S. typhimurium). 

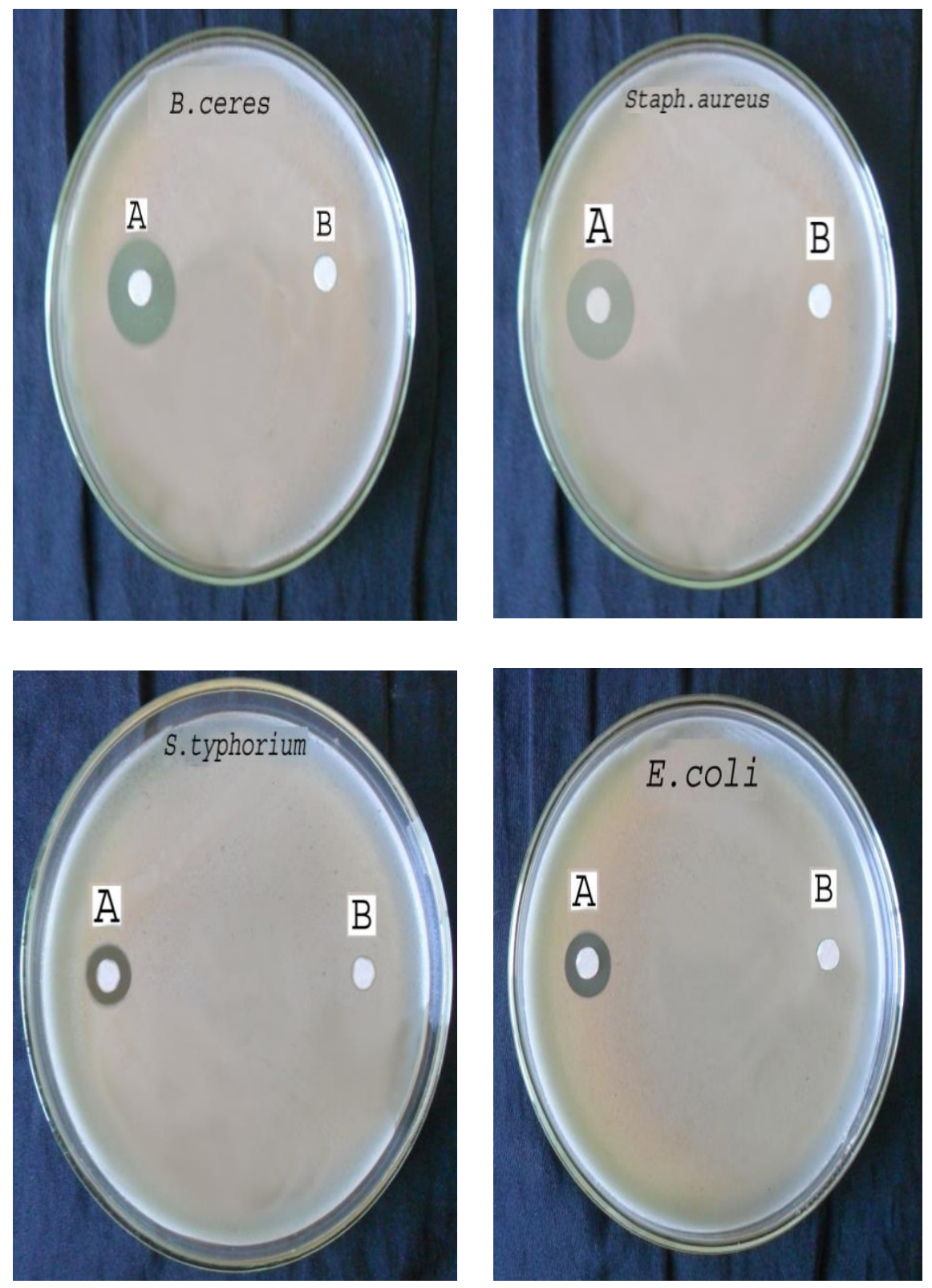

Fig.1.a.Antibacterial activity of fungal chitosan by disc diffusion method A: Fungal chitosan (1000 ppm) B: Control

Egypt. J.Microbiol. 50 (2015) 

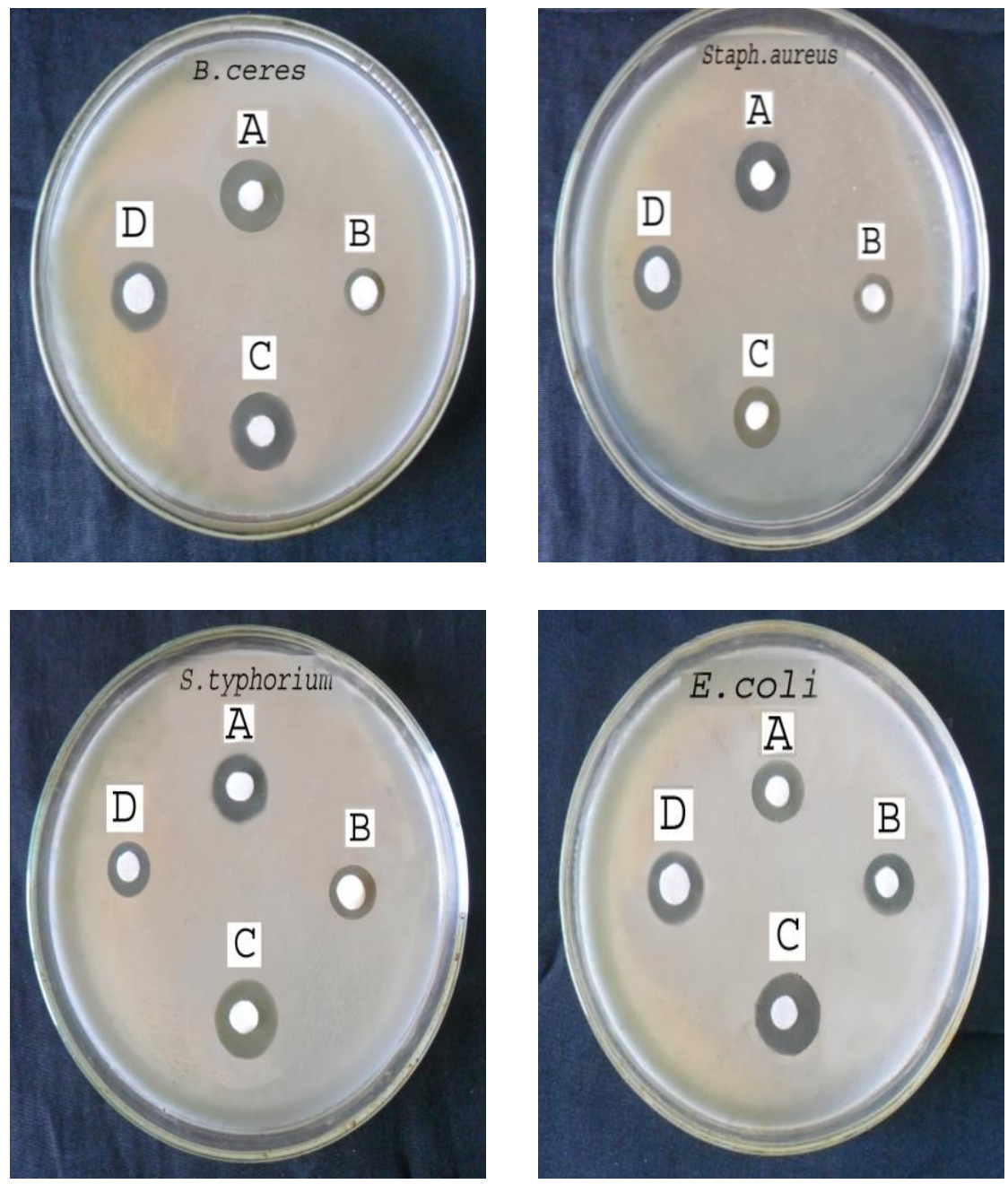

Fig. 1.b. Antibacterial activity of fungal chitosan by disc diffusion method. Fungal chitosan (1000ppm) of fungal chitosan compared to sodium benzoate and sodium nitrite
A: Fungal chitosan (1000 ppm)
C: Sodium benzoate
B: Fungal chitosan $(750 \mathrm{ppm})$

D: Sodium nitrite

\section{Inhibition percentage and minimal inhibitory concentration}

Data in Fig.2 show that inhibition in liquid culture of all strains increased with increasing concentrations of fungal chitosan and preservatives. Also, the data gave MIC values of $750 \mathrm{ppm}$ when fungal chitosan used against $E$. coli, $B$. cereus and Staphylococcus aureus while, the MIC was 1000 ppm when chitosan was used against $S$. typhimurium. 


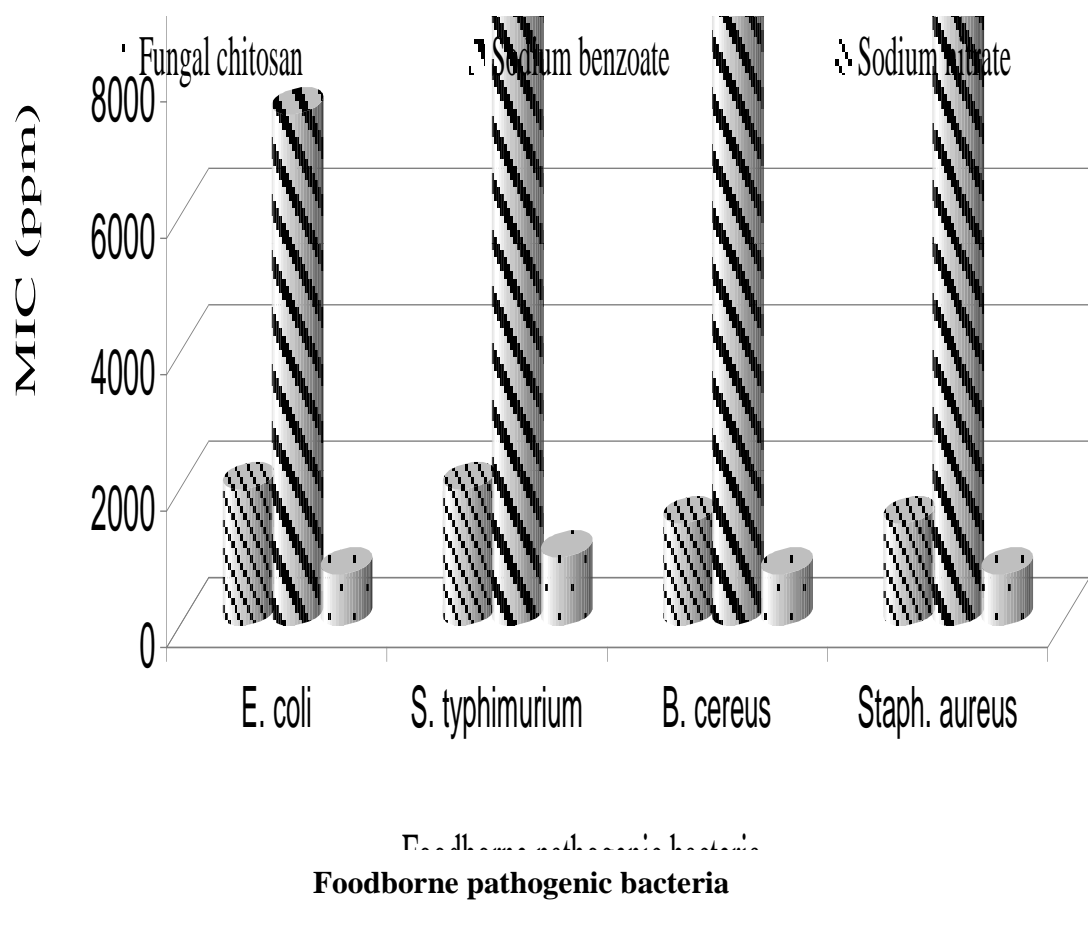

Fig. 2. Minimal inhibitory concentration (ppm) values of fungal chitosan compared to some preservatives against some foodborne pathogenic bacteria

These results are in harmony with Islam et al. (2011) who studied the effect of chitosan on the susceptibility of Staph. aureus and E. coli. They used different concentrations of chitosan namely 600, 800, 1000, 1200, 1300 and $1400 \mathrm{ppm}$. They found that the minimum inhibitory concentration (MIC) of the prepared chitosan was 1200 and 1300 ppm for Staph. aureus and E. coli, respectively.

It is worthily to mention that MIC of sodium benzoate was $7500 \mathrm{ppm}$ for $E$. coli and $10000 \mathrm{ppm}$ for S. typhimurium, B. cereus and Staph. aureus. While, MIC of sodium nitrite was 1500 ppm for Bacillus cereus and Staph. aureus and 2000 ppm for S. typhimurium and E. coli. These results are in agreement with Stanojevic et al. (2010) who investigated the antimicrobial effect of sodium benzoate and sodium nitrite on food-borne pathogenic bacteria such as Bacillus subtilis, Bacillus mycoides, Staphylococcus aureus, Escherichia coli, Pseudomonas fluorescens, Proteus sp. and Pseudomonas aeruginosa. They found the MIC for sodium benzoate was 5000 ppm while, MIC for sodium nitrite, it was 500 and 2000 ppm.

Effect of MIC of chitosan on the survival of pathogenic bacterial strains compared to some preservatives

Data in Fig. 3, 4, 5 and 6 showed that the counts of all pathogenic bacteria in the control treatment (without antibacterial agents) gradually increased with the

Egypt. J.Microbiol. 50 (2015) 
increasing of incubation period to reach their maximum values after $42 \mathrm{~h}$ for $E$. coli and 48 h for S. typhimurium, Staph. aureus and B. cereus. Data graphically illustrated in Fig 3 emphasize that the inhibition percentage for E. coli was $95.26 \%$ after $42 \mathrm{~h}$ when using MIC of chitosan while, $96.21 \%$ and $95 \%$ after $24 \mathrm{~h}$ and 30 $\mathrm{h}$ when using MIC of sodium benzoate and sodium nitrite, respectively. Also, data graphically illustrated by Fig. 4 showed that inhibition percentage of $S$. typhimurium reached to $95.16 \%, 95.15 \%$ and $95.01 \%$ after 48,24 and $30 \mathrm{~h}$ of incubation when using chitosan, sodium benzoate and sodium nitrite, respectively. On the other hand, data graphically illustrated by Fig. 5 emphasized that the inhibition percentage of B. cereus were 95.90, 95.79 and $95 \%$ after 24, 30 and $18 \mathrm{~h}$ of incubation when using MIC of chitosan, sodium benzoate and sodium nitrite, respectively. In addition, data graphically illustrated by Fig. 6 showed that the inhibition percentage of Staph. aureus was $95.13 \%$ after $30 \mathrm{~h}$ when chitosan applied, while the inhibition percentage was $95.93 \%$ after $24 \mathrm{~h}$ when using MIC of sodium benzoate and $95.02 \%$ after $30 \mathrm{~h}$ when using MIC of sodium nitrite.

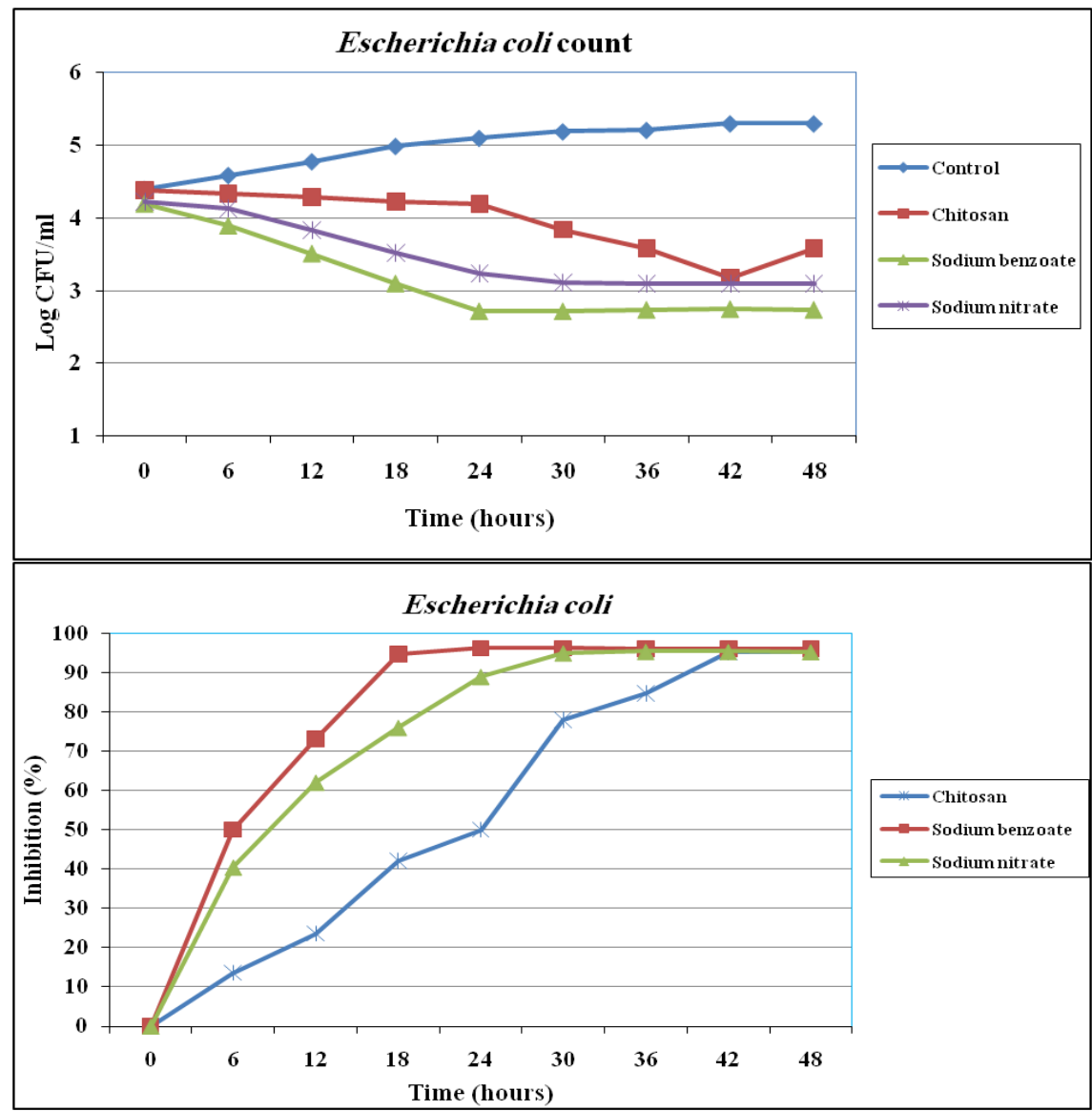

Fig. 3. Effect of MIC of chitosan, sodium benzoate and sodium nitrite on survival of $E$. coli. 

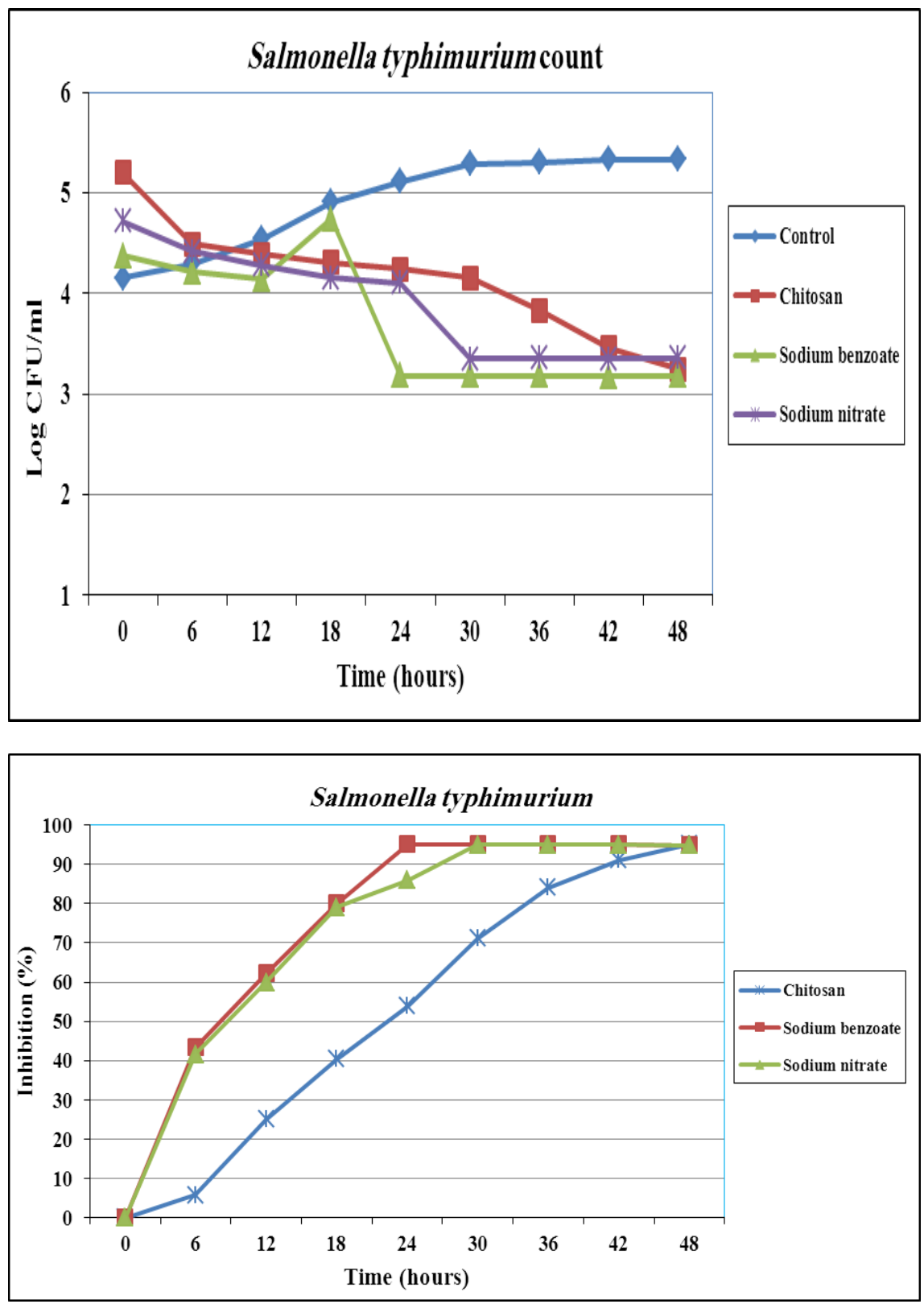

Fig. 4. Effect of MIC of chitosan, sodium benzoate and sodium nitrite on survival of S. typhimurium

Egypt. J.Microbiol. 50 (2015) 

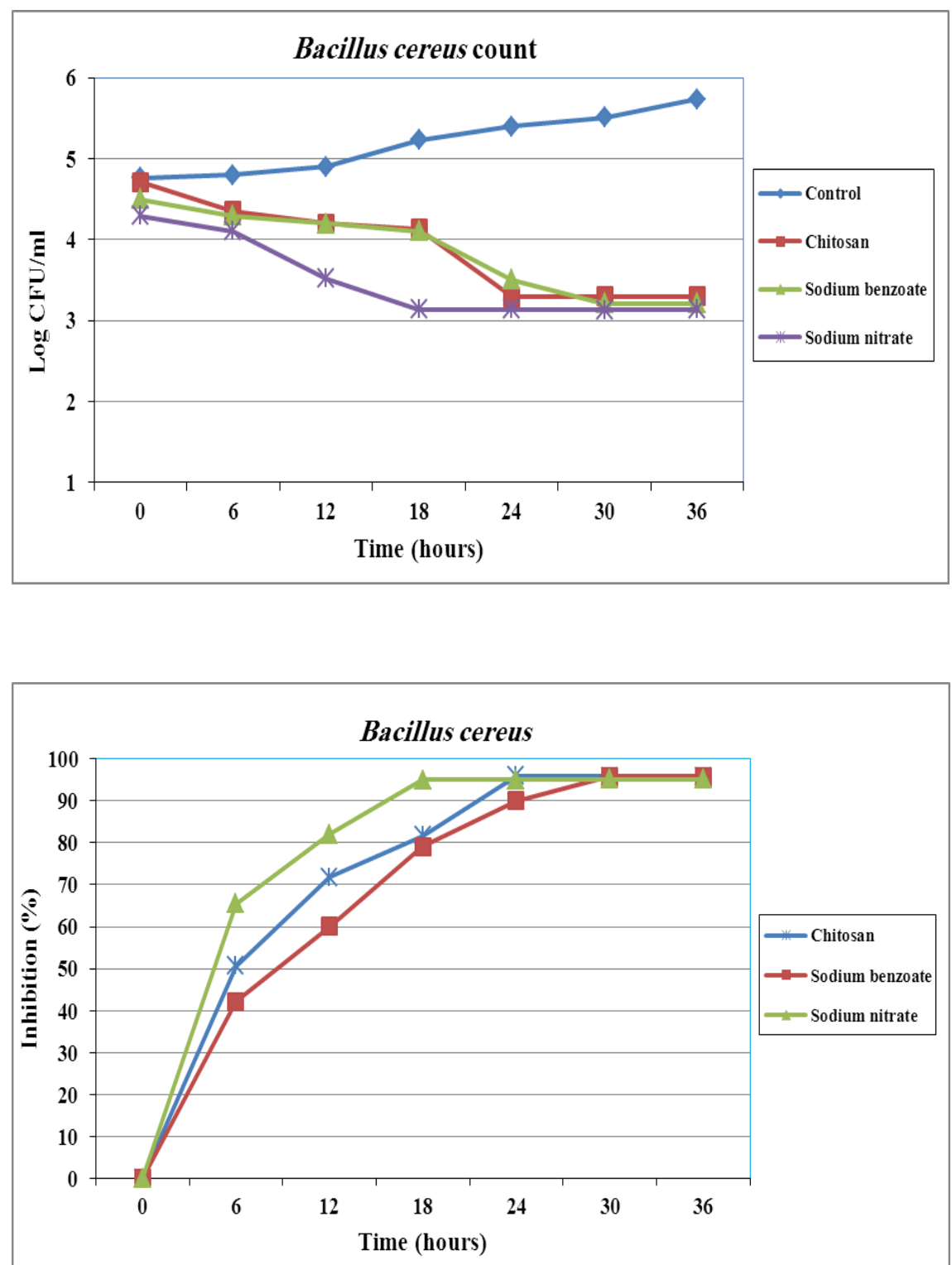

Fig. 5. Effect of MIC of chitosan, sodium benzoate and sodium nitrite on survival of B. cereus. 

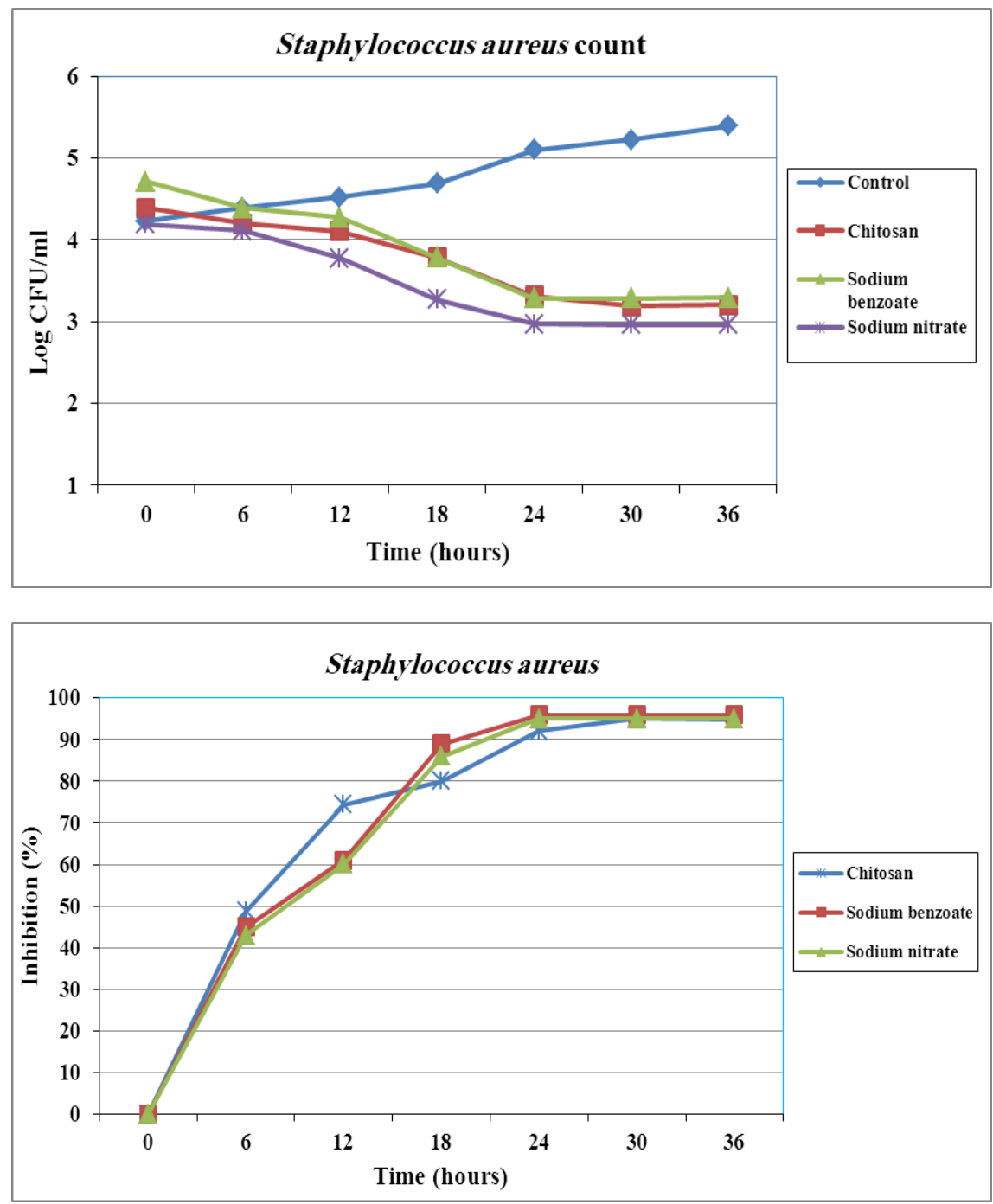

Fig. 6. Effect of MIC of chitosan, sodium benzoate and sodium nitrite on survival of Staph. aureus.

From the obtained data, it was worthwhile to mention that as has been previously reported (Tayel et al., 2011) chitosan is more effective on Gram positive bacteria than Gram negative bacteria.

\section{Conclusion and Recomendation}

In view of the obtained results, it was clearly that fungal chitosan showed good antibacterial activity against food borne pathogenic bacteria. Although this

Egypt. J.Microbiol. 50 (2015) 
chitosan was still less active than other chemical preservatives, it is edible and non-toxic for human health and likely a great deal more expensive.

\section{References}

Abd-El-Kareem, F. (2002) Integrated treatments between bio agents and chitosan on root rot diseases of pea plants under field conditions. Egypt J. Appl. Sci. 17, 257- 279.

Balicka-Ramisz, Aleksandra, Wojtasz-Pajak, Anna. Pilarczyk, Bogumila, Ramisz, A. and Laurans, L. (2005) "Antibacterial and Antifungal Activity of Chitosan". ISAH 2005 - Warsaw, Poland, 2: pp. 406-408.

Barakat, H.A. (2010) Application of the antifungal protein from Aspergillus giganteus on selected foodstuffs and its relation to quality and safety. Ph.D. Thesis, Fac. Agric., Benha Univ., Egypt.

Benhamou, N. and Theriault, G. (1992) Treatment with chitosan enhances resistance of tomato plants to the crown and root rot pathogens, Fusarium oxysporum f. sp. radicislycopersici. Physiol. Mol. Plant Pathol. 41, 33-52.

El-Mougy, Nehal S., Abd-El-Karem, F. and Abd-Alla, M.A. (2002) Postharvest diseases control: Preventive effect of chitosan and bio-agents against green and gray moulds of apple fruits. Egypt. J. Phytopathol. 30, 99-113.

Guirguis, O.W., Abd Elkader, M.F.H. and Nasrat, A.A. (2013) Enhancing antimicrobial activity for chitosan by adding Jojoba liquid wax. Materials Letters, 93, 353- 355 .

Islam, M.M., Masum, S.M., Mahbub, K.R. and Haque, M.Z. (2011) Antibacterial activity of crab-chitosan against Staphylococcus aureus and Escherichia coli. J. Adv. Sci. 2(4), 63-66.

Khalaf, Salwa A. (2004) Production and characterization of fungal chitosan under solidstate fermentation conditions. Inter. J. Agric. Biol. 6,1033-1036.

Logesh, A.R., Thillaimaharani, K.A., Sharmila, K., Kalaiselvam, M. and Raffi, S. M. (2012) Production of chitosan from endolichenic fungi isolated from mangrove environment and its antagonistic activity. J. Tropical Biomedicine, 2,140-143.

Shahidi, F., Arachchi, J.K.V. and You, J.J. (1999) Food applications of chitin and chitosan. Trends in Food Sci. Technol. 10, 37-51.

Stanojevic, D., Comic, L.J., Stefanovic, O. and Solujic-Sukdolak, S. (2010) In vitro synergistic antibacterial activity of Salvia officinalis L. and some preservatives. Arch. Biol. Sci., Belgrade, 62(1),175-183.

Tayel, A.A., Moussa, H.S., El- Tras, F.W., Elguindy, M.N. and Opwis, K. (2011) Antimicrobial textile treated with chitosan from Aspergillus niger mycelial waste. $J$. Biol. Macromolecules, 49, 241-245. 
Theis, T., Wedde, M., Meyer, V. and Stahl, U. (2003) The antifungal protein from Aspergillus giganteus causes membrane permeabilisation. Antimicrob. Agents Chemr. 47, 588-593.

Wu, T., Zivanovic, S., Draughon, F.A., Conway, W.S. and Sams, C.E. (2005) Physicochemical properties and bioactivity of fungal chitin and chitosan. J. Agric. Food Chem. 53, 3888-3894.

( Received $10 / 6 / 2015$;

accepted $11 / 10 / 2015)$

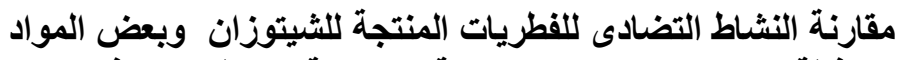

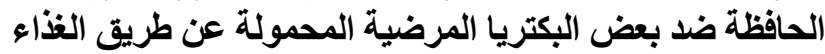

$$
\begin{aligned}
& \text { راشد عبدالفتاح زغلول حامد السيد أبوعلى، طلعت محمد الحسينى ، غنيمى }
\end{aligned}
$$

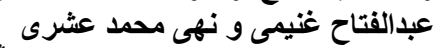

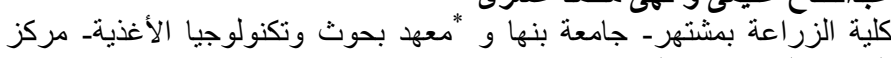

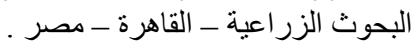

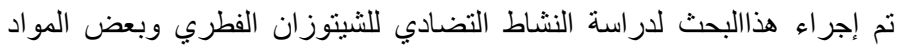

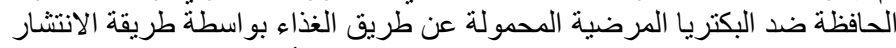

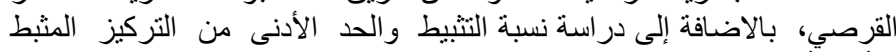

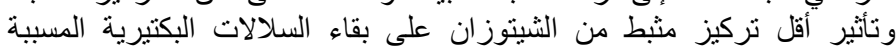

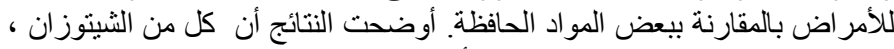

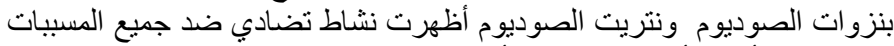

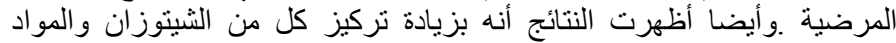

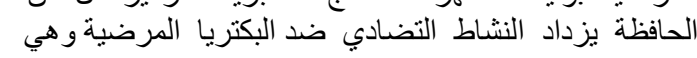
E. coli, S.typhimurium, B.cereus and Staph.aureus

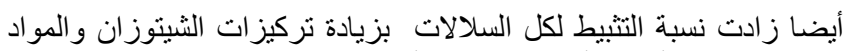

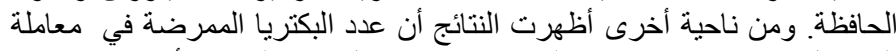

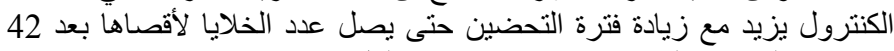

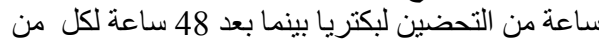

E. coli., S.typhimurium, B.cereus and Staph. aureus 